ARTICLE

\title{
Heterospin frustration in a metal-fullerene-bonded semiconductive antiferromagnet
}

\author{
Yongbing Shen (10 ${ }^{1 凶}$, Mengxing Cui ${ }^{1}$, Shinya Takaishi (1) ${ }^{1}$, Hideyuki Kawasoko (1) ${ }^{1}$, Kunihisa Sugimoto (1) ${ }^{2}$, \\ Takao Tsumuraya (1) ${ }^{3}$, Akihiro Otsuka (1) 4,5, Eunsang Kwon ${ }^{6}$, Takefumi Yoshida', Norihisa Hoshino (1) ${ }^{7}$, \\ Kazuhiko Kawachi ${ }^{8}$, Yasuhiko Kasama ${ }^{8}$, Tomoyuki Akutagawa ${ }^{7}$, Tomoteru Fukumura ${ }^{1,9}$ \& \\ Masahiro Yamashita1,10凶
}

Lithium-ion-encapsulated fullerenes $\left(\mathrm{Li}^{+} @ \mathrm{C}_{60}\right)$ are 3D superatoms with rich oxidative states. Here we show a conductive and magnetically frustrated metal-fullerene-bonded framework $\left\{\left[\mathrm{Cu}_{4}\left(\mathrm{Li} @ \mathrm{C}_{60}\right)(\mathrm{L})(\mathrm{py})_{4}\right]\left(\mathrm{NTf}_{2}\right) \text { (hexane) }\right\}_{n} \quad$ (1) $\quad(L=1,2,4,5$-tetrakis (methanesulfonamido) benzene, $\mathrm{py}=$ pyridine, $\mathrm{NTf}_{2}{ }^{-}=$bis(trifluoromethane)sulfonamide anion) prepared from redox-active dinuclear metal complex $\mathrm{Cu}_{2}(\mathrm{~L})(\mathrm{py})_{4}$ and lithium-ion-encapsulated fullerene salt ( $\left.\mathrm{Li}^{+} @ \mathrm{C}_{60}\right)\left(\mathrm{NTf}_{2}{ }^{-}\right)$. Electron donor $\mathrm{Cu}_{2}(\mathrm{~L})(\mathrm{py})_{2}$ bonds to acceptor $\mathrm{Li}^{+} @ \mathrm{C}_{60}$ via eight $\mathrm{Cu}-$ $\mathrm{C}$ bonds. $\mathrm{Cu}-\mathrm{C}$ bond formation stems from spontaneous charge transfer (CT) between $\mathrm{Cu}_{2}(\mathrm{~L})(\mathrm{py})_{4}$ and $\left(\mathrm{Li}^{+} @ \mathrm{C}_{60}\right)\left(\mathrm{NTf}_{2}{ }^{-}\right)$by removing the two-terminal py molecules, yielding triplet ground state $\left[\mathrm{Cu}_{2}(\mathrm{~L})(\mathrm{py})_{2}\right]^{+}\left(\mathrm{Li}^{+} @ \mathrm{C}_{60^{\circ}}{ }^{-}\right)$, evidenced by absorption and electron paramagnetic resonance (EPR) spectra, magnetic properties and quantum chemical calculations. Moreover, $\mathrm{Li}^{+} @ \mathrm{C}_{60}{ }^{\circ-}$ radicals $(S=1 / 2)$ and $\mathrm{Cu}^{2+}$ ions $(S=1 / 2)$ interact antiferromagnetically in triangular spin lattices in the absence of long-range magnetic ordering to $1.8 \mathrm{~K}$. The low-temperature heat capacity indicated that compound $\mathbf{1}$ is a potential candidate for an $S=1 / 2$ quantum spin liquid (QSL).

\footnotetext{
${ }^{1}$ Department of Chemistry, Graduate School of Science, Tohoku University, 6-3 Aza-Aoba, Aramaki, Sendai 980-8578, Japan. ${ }^{2}$ Diffraction \& Scattering Division Synchrotron Radiation Research Institute, Hyogo 679-5198, Japan. ${ }^{3}$ Priority Organization for Innovation and Excellence, Kumamoto University, 2-391 Kurokami, Kumamoto 860-8555, Japan. ${ }^{4}$ Division of Chemistry, Graduate School of Science, Kyoto University, Sakyo-Ku, Kyoto 606-8502, Japan.

${ }^{5}$ Research Center for Low Temperature and Materials Sciences, Kyoto University, Sakyo-Ku, Kyoto 606-8501, Japan. ${ }^{6}$ Research and Analytical Center for Giant Molecules, Tohoku University, 6-3, Aramaki-Aza-Aoba, Aoba-ku, Sendai 980-8578, Japan. ${ }^{7}$ Institute of Multidisciplinary Research for Advanced Materials, Tohoku University, 2-1-1 Katahira, Aoba-Ku, Sendai 980-8577, Japan. ${ }^{8}$ Idea International Co., Ltd., 1-15-35 Sagigamori, Aoba-ku, Sendai 981-0922, Japan. ${ }^{9}$ Advanced Institute for Materials Research and Core Research Cluster, Tohoku University, Sendai 980-8577, Japan. ${ }^{10}$ School of Materials Science and Engineering, Nankai University, Tianjin 300350, China. ${ }^{凶}$ email: shen.yongbing.b1@tohoku.ac.jp; yamasita@agnus.chem.tohoku.ac.jp
} 
S ince the pure form of the lithium-ion-encapsulated fullerene salt $\left[\mathrm{Li} @ \mathrm{C}_{60}\right]\left(\mathrm{SbCl}_{6}\right)$ was isolated and structurally determined by X-ray diffraction analysis in $2010^{1}$, studies on this smallest endohedral metallofullerene (EMF) have taken precedence over photoinduced electron transfer (ET) in noncovalent donor-acceptor (D-A) complexes ${ }^{2-6}$, covalent metal complexes $^{7}$, organic photovoltaics ${ }^{8}$, and molecular electronics 9 over the past decade because of the salt's unique structure and electronic properties relative to pristine $\mathrm{C}_{60}{ }^{10-14}$. Although the optical bandgap $\left(E_{\mathrm{g}}\right)$ is very close to that of pristine $\mathrm{C}_{60}$, the lowest unoccupied molecular orbital (LUMO) of $\mathrm{Li}^{+} @ \mathrm{C}_{60}$ has been observed to decline significantly to $-3.90 \mathrm{eV}$ with an initial reduction potential at $-0.39 \mathrm{~V}$ versus $\mathrm{Fc}_{\mathrm{Fc}}{ }^{+}$in $o$ dichlorobenzene $(o-\mathrm{DCB})^{1}$. Furthermore, the oxidisation state of $\mathrm{Li}^{+} @ \mathrm{C}_{60}$ can be easily tuned from $1+$ to 3 - by external chemical stimuli to realise various electronic states ${ }^{1}$. Therefore, this compound has been widely used as a $\pi$-electron acceptor owing to the small reorganisation energy required, which leads to highly delocalised $\pi$-electrons over a $3 \mathrm{D}$ sphere ${ }^{2,3}$. It is possible that $\mathrm{Li}^{+} @ \mathrm{C}_{60}$ can be doped by alkali metals to produce $\mathrm{A}_{3}\left(\mathrm{Li} @ \mathrm{C}_{60}\right)$ species $\left(\mathrm{A}=\mathrm{K}^{+}, \mathrm{Rb}^{+}\right.$, and $\left.\mathrm{Cs}^{+}\right)$in imitation of $\mathrm{A}_{3} \mathrm{C}_{60}$ superconductors with three electrons accommodated in the triply degenerated LUMO ${ }^{15-18}$. In particular, the emergence of $\mathrm{Li}^{+} @ \mathrm{C}_{60}{ }^{\circ}-$ requires a milder chemical oxidant than for $\mathrm{C}_{60}{ }^{\circ-}$. Such a low reduction potential provides many opportunities for coordination chemistry. According to the Mulliken theory ${ }^{19-22}$, the formation of the CT complex requires efficient orbital overlap between the highest occupied molecular orbital (HOMO) of D and the LUMO of A. The CT interactions in the ground state increase with a decrease in the energy difference between the HOMO of D and LUMO of A. In this regard, Martin and co-workers reported several CT complexes between comparatively strong electron donors such as $\pi$-extended tetrathiafulvalene derivatives and fullerenes ${ }^{23,24}$. Additionally, Yamada et al. observed a triplet charge-separated state by laserexciting a curved $\pi$-surface donor and $\mathrm{Li}^{+} @ \mathrm{C}_{60}$ in solution ${ }^{3}$.

Although $\mathrm{C}_{60}$ is an ideal ligand to realise topological architectures owing to its isotropic coordination environment ${ }^{25}$, to date, reports on the preparation of electrically conductive and magnetically frustrated solids based on $\mathrm{Li}^{+} @ \mathrm{C} 60$ remain elusive. On the other hand, the $S=1 / 2$ electronic system holds promise for exploring interesting quantum phenomena such as unconventional superconductivity ${ }^{26-29}$ and QSLs, which are commonly observed in triangular or kagomé lattices ${ }^{30-36}$. Herein, we selected an electronically active donor, $\mathrm{Cu}_{2}(\mathrm{~L})(\mathrm{py})_{4}$, and a $3 \mathrm{D}$ chargetuneable metallofullerene, $\mathrm{Li}^{+} @ \mathrm{C}_{60}$, as both the ligand and electron acceptor to construct a conductive and spin-frustrated framework based on the Mulliken theory.

In this work, an $S=1 / 2$ electronic framework $\left\{\left[\mathrm{Cu}_{4}\left(\mathrm{Li}^{+} @ \mathrm{C}_{60}\right)\right.\right.$ (L) (py) $\left.)_{4}\right]\left(\mathrm{NTf}_{2}\right)$ (hexane) $\}_{n}$ (1) is isolated by constructing the donor and acceptor. The donor is bonded to the acceptor via $\mathrm{Cu}-\mathrm{C}$ bonds. It is noteworthy that the HOMO of $\mathrm{Cu}_{2}(\mathrm{~L})(\text { py })_{4}$ has the equivalent energy level of the LUMO of $\mathrm{Li}^{+} @ \mathrm{C}_{60}$, thereby facilitating CT interactions in the ground state. From our calculations, we find that the $d_{\mathrm{xz}}$ orbitals of the $\mathrm{Cu}$ ions in $\mathrm{Cu}_{2}(\mathrm{~L})(\mathrm{py})_{4}$ are delocalised and strongly coupled with the $\mathrm{N}\left(p_{\mathrm{z}}\right)$ orbitals $(\pi-$ electrons) of the ligand, thereby yielding delocalised electrons in the HOMO. In $\mathbf{1}$, the four-terminal $d_{x z}$ orbitals of $\mathrm{Cu}$ ions coordinate with one $\mathrm{Li}^{+} @ \mathrm{C}_{60}$ cage and the remaining four $\mathrm{Cu}$ ions coordinate with the next $\mathrm{Li}^{+} @ \mathrm{C}_{60}$ cage to form an infinitely scaled 1D chain structure. The four $\mathrm{Cu}(\mathrm{L})(\mathrm{py})$ sites transfer a single electron into the $\mathrm{Li}^{+} @ \mathrm{C}_{60}$ cage, and the resulting four $\mathrm{Cu}^{2+}(S=1 / 2)$ ions and $\mathrm{Li}^{+} @ \mathrm{C}_{60}{ }^{-}-(S=1 / 2)$ interact with each other and exhibit magnetic frustration in a triangular-like lattice. Our study demonstrates long-range electrical conductivity $(\sigma)$ and spin frustration using $\mathrm{Li}^{+} @ \mathrm{C}_{60}$ superatoms in such a bonded D-A-type framework.

\section{Results and discussion}

Metal-fullerene bonded donor-acceptor-type framework. Compound 1 was synthesised by reaction of $\mathrm{Cu}_{2}(\mathrm{~L})(\mathrm{py})_{4}$ and $\left(\mathrm{Li}^{+} @ \mathrm{C}_{60}\right)\left(\mathrm{NTf}_{2}^{-}\right)$with a molar ratio of 2:1 in $o$-DCB solution. It crystallises in the triclinic $P_{1}^{-}$space group with the unit-cell dimensionality of $a=9.9963(3) \AA, b=13.3087(3) \AA, c=19.7031(5)$ $\AA, \alpha=77.323(2)^{\circ}, \beta=76.572(2)^{\circ}$, and $\gamma=69.500(2)^{\circ}$ at $120 \mathrm{~K}$. One $\mathrm{Li}^{+} @ \mathrm{C}_{60}$ cage coordinates with four $\mathrm{Cu}$ ions from four $\mathrm{Cu}_{2}(\mathrm{~L})(\mathrm{py})_{2}$ molecules (Fig. 1a), and the remaining four $\mathrm{Cu}$ ions coordinate with the next $\mathrm{Li}^{+} @ \mathrm{C}_{60}$ cage to afford infinite 1D ladder-like structures along the $b$-axis (Fig. 2a). Each $\mathrm{Cu}$ ion exhibits an equivalent of five coordination numbers (two $\mathrm{Cu}-\mathrm{C}$ and three $\mathrm{Cu}-\mathrm{N}$ bonds) in a distorted trigonal bipyramid geometry (Supporting Information Fig. 1). The rectangular plane formed by the four $\mathrm{Cu}$ ions perfectly divides the $\mathrm{C}_{60}$ cage into two (Fig. 1b), and the shell-like $\mathrm{Li}^{+}$ion is off-centred and localised above or below the $\mathrm{Cu}$ plane with thermal ellipsoids at $50 \%$ probability. Similar $\mathrm{Li}^{+}$-ion arrangements are also observed in the other forms of $\mathrm{Li}^{+} @ \mathrm{C}_{60}$ salts $^{37,38}$. The inner $\mathrm{Li}^{+}$ion coordinates with the six-carbon ring with $\mathrm{Li}-\mathrm{C}$ bond lengths in the range of 2.337-2.527 $\AA$, which are consistent with the reported results ${ }^{7,39}$. The encapsulated $\mathrm{Li}^{+}$ions should strengthen the $\pi$ backbonding from the transition-metal centre to the fullerene cage; however, the $\mathrm{Cu}$ ions do not coordinate with the rings of the sixcarbon (pink atoms in Fig. 2) owing to the highly symmetrical array of the four $\mathrm{Cu}$ ions.

The benzene ring of the ligand is slightly distorted (Supporting Information Fig. 2), and the bond patterns indicate the loss of aromaticity (Fig. 1c). On the other hand, the hexane molecules are trapped inside the squared structure of $\left[\mathrm{Cu}_{2}(\mathrm{~L})(\mathrm{py})_{3}\left(\mathrm{Li}^{+} @ \mathrm{C}_{60}\right)\right]_{2}$ and strongly disordered along two lines (Supporting Information Fig. 3). Close to the square structure, the $\mathrm{NTf}_{2}{ }^{-}$molecules interact
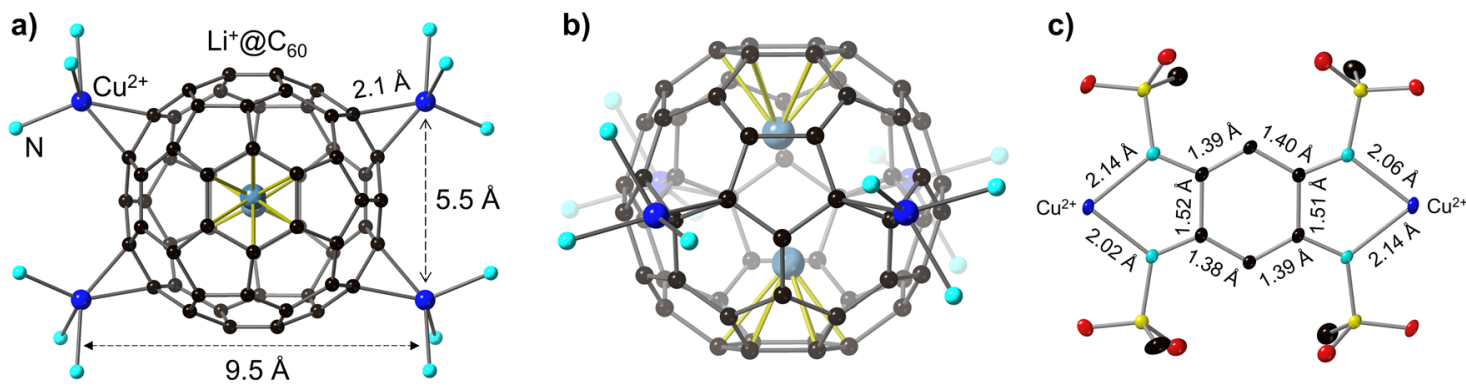

Fig. 1 Crystal structures of $\mathbf{C u}_{\mathbf{4}}-\mathbf{L i}{ }^{+} @ \mathbf{C}_{\mathbf{6 0}}$ and $\left.\mathbf{C u}_{\mathbf{2}} \mathbf{(} \mathbf{L}\right)$. a The coordination geometry of $\left[\mathrm{Cu}(\mathrm{N})_{3}\right]_{4}\left(\mathrm{Li}^{+} @ \mathrm{C}_{60}\right)$ and the arrangement of $\mathrm{Li}-\mathrm{ion}$. One $\mathrm{Li}+@ \mathrm{C}_{60}$ coordinates with four $\mathrm{Cu}$ ions. The four $\mathrm{Cu}$ ions form a rectangular-like plane with a length and width of 9.5 and $5.5 \AA$, respectively. b The Li-ion coordinates with six carbon-ring and locates above or below the Cu-plane with thermal ellipsoids at the 50\% probability. The Cu-plane perfectly splits the Li+@ $\mathrm{C}_{60}$ cage in half. c The structure of the donor, $\mathrm{Cu}_{2}(\mathrm{~L})$ and its bond length. Colour code: $\mathrm{C}$ (black), $\mathrm{Cu}$ (blue), N (cyan), S (yellow), O (red) and Li (pastel blue). 

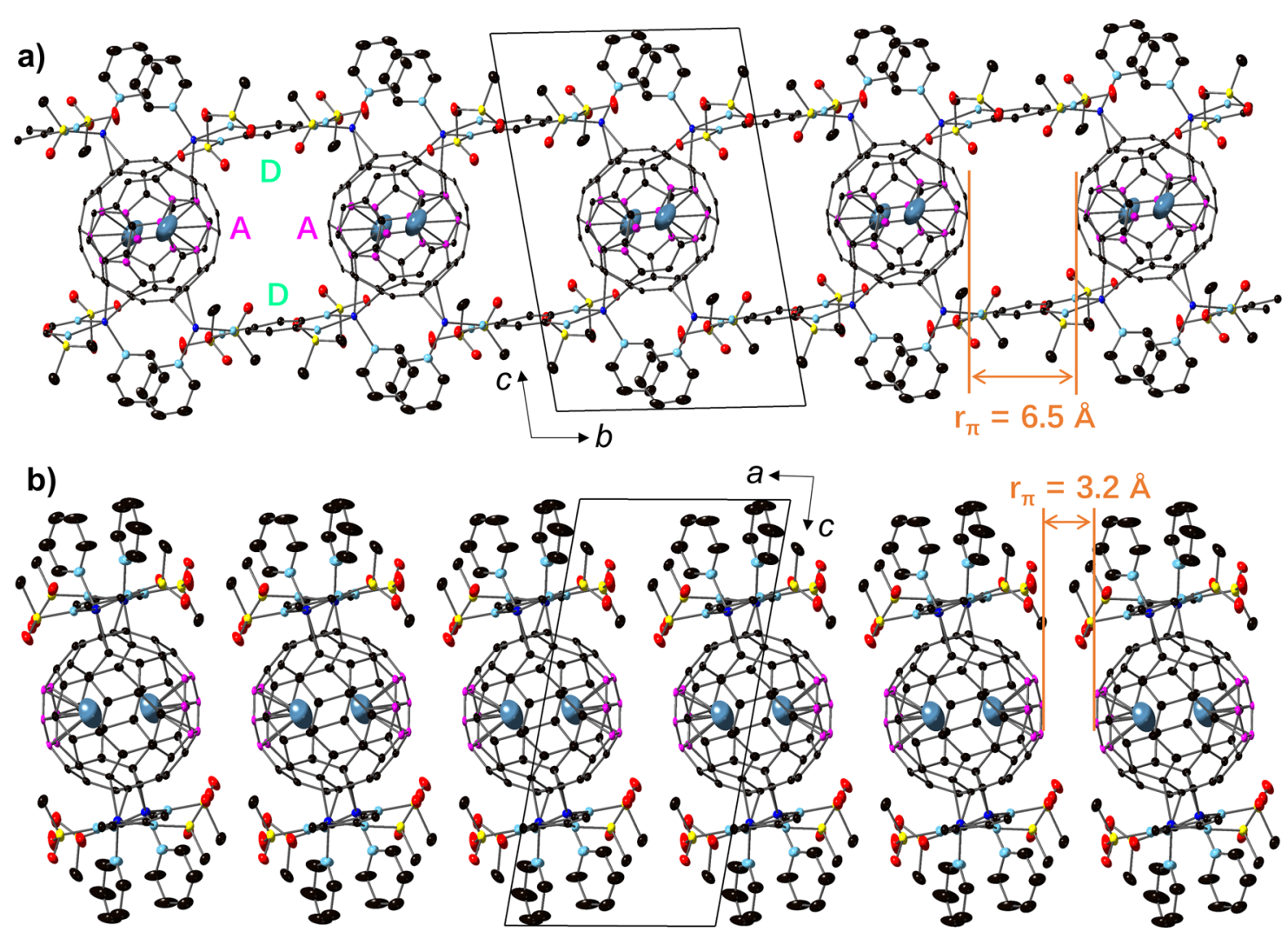

Fig. 2 The structure arrangements of the ladder-like chains. a 1D ladder-like structure along the $b$-axis in the $b c$ plane (anion $\mathrm{NTf}_{2}{ }^{-}$and hexane molecules are omitted). One $\mathrm{Li}^{+} @ \mathrm{C}_{60}$ cage coordinates with four $\mathrm{Cu}$ ions and the remaining four-terminal $\mathrm{Cu}$ ions coordinate with the adjacent $\mathrm{Li}^{+} @ \mathrm{C}_{60} \mathrm{cag}_{\mathrm{g}}$ to form a 1D ladder-like structure. Distance $r_{\pi}$ between adjacent $\mathrm{Li}^{+} @ \mathrm{C}_{60}$ cages is $6.5 \AA$. The $\mathrm{Li}$ atoms are off-centred and polarised above/below the Cu plane. b Top view of the 1D ladder-like structure in the ac plane. Each structure stacks along the $a$-axis to form a 2D interacting sheet with intermolecular distance = $3.2 \AA$ between two Li+@ @ 60 cages. Colour code: Cu (blue), sulphur (yellow), oxygen (red), nitrogen (pastel cyan), carbon (black/pink). Hydrogen atoms are omitted for clarity.

electrostatically with ligands through hydrogen bonds. Inside the ladder chain, the $\pi \cdots \pi$ distance $\left(r_{\pi}\right)$ between the two $\mathrm{Li}^{+} @ \mathrm{C}_{60}$ cages is $6.5 \AA$ (Fig. 2a), indicating well-separated $\pi$ electrons along the $b$ axis. The $1 \mathrm{D}$ ladder structures self-stack along the $a$-axis to form $2 \mathrm{D}$ interacting nanosheets with $r_{\pi}$ of $3.2 \AA$ (Fig. 2b). To determine the structure phase purity, the temperature dependence of crystal structures were determined at various temperature points $(25,50$, 100,200 , and $300 \mathrm{~K}$ ) by using synchrotron radiation. The structure analysis indicated that there are no structural changes or distortions in $25-300 \mathrm{~K}$ (PXRD patterns in Supporting Information Fig. 4). Above $100 \mathrm{~K}$, we did not detect the $\mathrm{Li}^{+}$position because of the fast motion of the $\mathrm{Li}^{+}$ion inside the cage. Below $100 \mathrm{~K}$, the $\mathrm{Li}^{+}$ion was disordered and localised at two equivalent positions due to the symmetry. As the localised $\mathrm{Li}^{+}$ions strongly attract the negative radicals (via $\mathrm{Li}-\mathrm{C}$ bonds), the $\mathrm{C}_{60^{\circ}}{ }^{-}$radicals localised on the sixcarbon ring (pink atoms in Fig. 2).

Spontaneous charge transfer between $\mathrm{Cu}_{2}(\mathrm{~L})(\mathrm{py})_{4}$ and $\left(\mathrm{Li}^{+} @ \mathrm{C}_{60}\right)$ $\left(\mathrm{NTf}_{2}{ }^{-}\right)$by precise control of the redox activities. Figure 3 a shows the $\mathrm{CV}$ plot to $\mathrm{Fc} / \mathrm{Fc}^{+}$. Four reversible redox processes with the first and second oxidisation potentials are observed at -0.36 and $-0.04 \mathrm{~V}$, respectively. Meanwhile, the first and second reduction potentials are observed at -0.92 and $-1.08 \mathrm{~V}$, respectively. The potential at $-0.36 \mathrm{~V}$ corresponds to the first oxidisation process of $\mathrm{Cu}_{2}(\mathrm{~L})(\mathrm{py})_{4}$ to $\left[\mathrm{Cu}_{2}(\mathrm{~L})(\mathrm{py})_{4}\right]^{+}$. In this regard, Aoyagi et al. reported that the first reduction process from $\mathrm{Li}^{+} @ \mathrm{C}_{60}$ to $\mathrm{Li}$ $+@ \mathrm{C}_{60}{ }^{-}-$occurs at $-0.39 \mathrm{eV}$ in $o-\mathrm{DCB}$ versus $\mathrm{Fc} / \mathrm{Fc}^{+1}$. Consequently, the $\mathrm{HOMO}$ energy level of $\mathrm{Cu}_{2}(\mathrm{~L})(\mathrm{py})_{4}$ can be simply treated as equivalent to the LUMO energy level of $\mathrm{Li}^{+} @ \mathrm{C}_{60}$ if the dissolution-free energy effect is ignored (Fig. 3b). According to the Mulliken theory, ET from $\mathrm{Cu}_{2}(\mathrm{~L})(\mathrm{py})_{4}$ (donor) to $\mathrm{Li}^{+} @ \mathrm{C}_{60}$ (acceptor) can spontaneously occur without external energy to generate a triplet ground state $\left[\mathrm{Cu}_{2}(\mathrm{~L})(\mathrm{py})_{4}\right]^{+}\left[\mathrm{Li}^{+} @ \mathrm{C}_{60^{\circ}}\right]$. The solution-state absorption spectra in Fig. $3 \mathrm{c}$ evidence this mechanism. $\left(\mathrm{Li}^{+} @ \mathrm{C}_{60}\right)\left(\mathrm{NTf}_{2}{ }^{-}\right)$does not show any absorption band from 750 to $1500 \mathrm{~nm}$ whereas $\mathrm{Cu}_{2}(\mathrm{~L})(\mathrm{py})_{4}$ shows a strong and broadband at $920 \mathrm{~nm}$. Once the two pristine molecules are mixed in $o$-DCB, two new bands at 886 and $1032 \mathrm{~nm}$ are observed, strongly indicating that $\mathrm{Li}^{+} @ \mathrm{C}_{60} \cdot-$ is generated ${ }^{40}$. Moreover, the strong band at $920 \mathrm{~nm}$ in $\mathrm{Cu}_{2}(\mathrm{~L})(\mathrm{py})_{4}$ vanishes from the mixed solution, strongly indicating ET occurrence. The solid-state absorption spectrum of $\mathbf{1}$ shows several broad absorption bands at $1.30,1.91,2.42$, and $3.48 \mathrm{eV}$ (Supporting Information Fig. 5), where the band at $1.30 \mathrm{eV}$ extends to the IR region (inset of Supporting Information Fig. 5), which indicates that $\mathbf{1}$ has a small optical bandgap $\left(E_{\mathrm{g}}\right)$. Figure $3 \mathrm{~d}$ shows the Tauc plot of the Kubelka-Munk-transformed spectrum, with $E_{\mathrm{g}}=0.57 \mathrm{eV}$, as obtained from a linear fit to the low-energy onset of absorption. However, it is difficult to assign the $\mathrm{Li}^{+} @ \mathrm{C}_{60^{-}}-$band owing to absorption-band superpositions. Nevertheless, the generated $\mathrm{Li}$ $+@ \mathrm{C}_{60}{ }^{-}-$can be detected by the EPR spectra. Figure $3 \mathrm{e}$ shows the temperature dependence of the EPR spectra of 1 for $3.5-300 \mathrm{~K}$ with all spectra showing two EPR active bands. At the lower magnetic field, parallel $g_{\text {II }}$ values of 2.45(3), 2.32(1), and perpendicular $g_{\perp}$ value of $2.09(1)$ are observed at $300 \mathrm{~K}$. The $g$ values and peak-to-peak linewidth, $\Delta H_{\mathrm{pp}}=217.5(4) \mathrm{G}$, are entirely consistent with the $\mathrm{Cu}^{2+}$ ion $(S=1 / 2)^{41,42}$. Another weak signal observed near the $\mathrm{Cu}^{2+}$ signal with $g=2.0008(3)$ and $\Delta H_{\mathrm{pp}}=$ 
a)
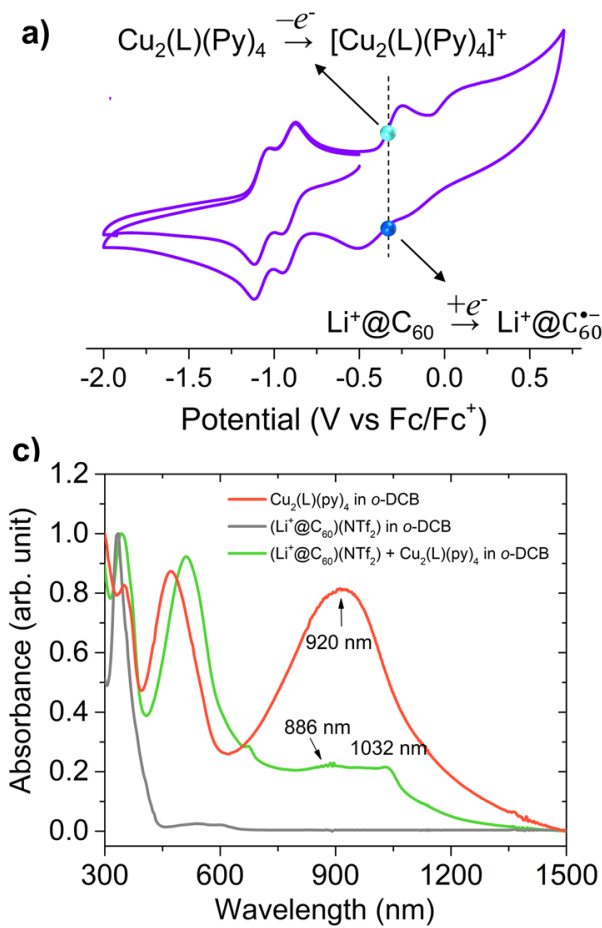

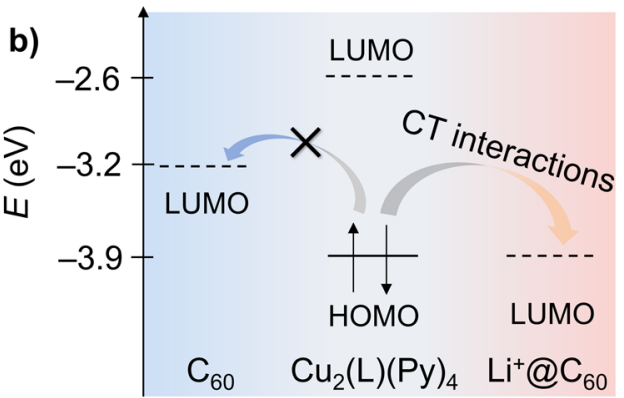

d)

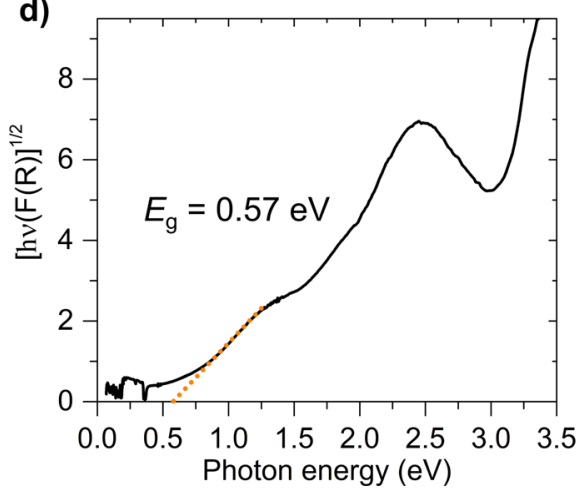

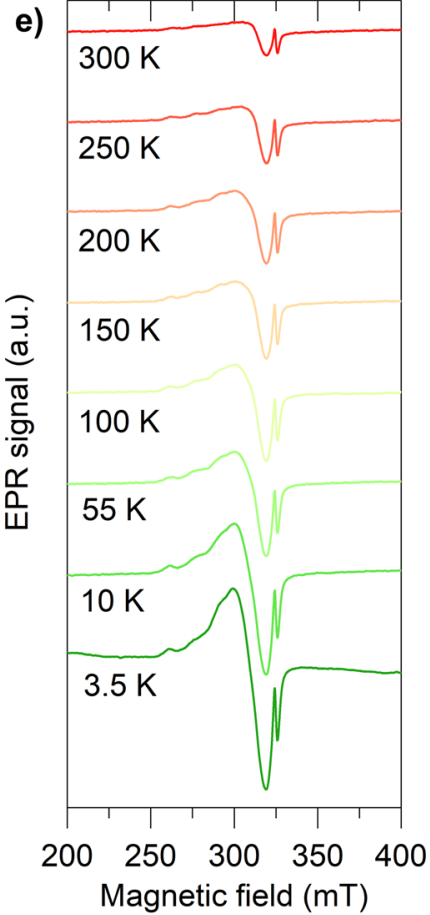

Fig. 3 Spectroscopic characterization. a Cyclic voltammogram ( -2.0 to $0.8 \mathrm{~V}$ versus $\left.\mathrm{Fc} / \mathrm{Fc}^{+}\right)$of $\mathrm{Cu}_{2}(\mathrm{~L})(\mathrm{py})_{4}$ in $0-\mathrm{DCB}$ with $0.1 \mathrm{M}$ TBAPF 6 as the supporting electrolyte. The pale blue dot at $E=-0.39 \mathrm{eV}$ represents the first reduction potential from $\mathrm{Li}^{+} @ \mathrm{C}_{60} \mathrm{to} \mathrm{Li}^{+} @ \mathrm{C}_{60}{ }^{\bullet-}$. b Schematic of chargetransfer interactions of $\mathrm{HOMO}$ and LUMO orbital energies between $\mathrm{Cu}_{2}(\mathrm{~L})(\mathrm{py})_{4}$ and $\mathrm{Li}^{+} @ \mathrm{C}_{60}$ calculated from the cyclic voltammogram. The $\mathrm{HOMO}$ energy level of $\mathrm{Cu}_{2}(\mathrm{~L})(\mathrm{py})_{4}$ is identical to the LUMO energy level of $\mathrm{Li}^{+} @ \mathrm{C}_{60}$, indicating strong CT interactions. c In situ solution-state UV-Vis-NIR absorption spectra at room temperature. $\mathbf{d}$ Tauc plot of room-temperature diffuse reflectance UV-vis-NIR spectra of $\mathbf{1}$ from 0.05 to $3.3 \mathrm{eV}$, obtained via Kubelka-Munk transforms $(F(R)$ ) for indirect allowed transition. The optical bandgap is determined as $0.57 \mathrm{eV}$ by the linear fit (orange dots) of absorption onset in the NIR energy region. e First-derivative solid-state X-band absorption EPR spectra of $\mathbf{1}$ for 3.5-300 K.

8.1(2) $\mathrm{G}$, signifies the presence of electronically active $\mathrm{Li}^{+} @ \mathrm{C}_{60^{\circ}}{ }^{-}$ radical $3,40,43$. However, it is difficult to assign significant interactions between $\mathrm{Cu}^{2+}$ ions and $\mathrm{Li}^{+} @ \mathrm{C}_{60}{ }^{-}$- radical from the EPR spectra, probably owing to the superposition of the two characterised bands, but the spectra demonstrate that spontaneous ET occurs from $\mathrm{Cu}_{2} \mathrm{~L}(\mathrm{py})_{4}$ to $\mathrm{Li}^{+} @ \mathrm{C}_{60}$ and $\mathbf{1}$ remains in a triplet ground state up to $3.5 \mathrm{~K}$.

$S=1 / 2$ heterospin frustration between $\mathrm{Cu}^{2+}$ and $\mathrm{Li}^{+} @ \mathrm{C}_{60}{ }^{--}$in the ladder-like chains. The intensity of main peaks in the EPR spectra mimics the thermal dependence of the magnetic susceptibility $(\chi)$. The $\chi-T$ plot of $\mathbf{1}$ does not show any magnetic phase transition from 1.8 to $300 \mathrm{~K}$ under $1 \mathrm{~T}$ (Fig. $4 \mathrm{a}$ ) and $4 \mathrm{~T}$ fields (Supporting Information Fig. 6), thereby indicating no long-range magnetic ordering. In addition, no sign of a spin-glass state is observed in the rectangular $\mathrm{Cu}$ lattices, as there is no deviation between the zero-field-cooled (ZFC) and field-cooled (FC) measurements. This suggests that $\mathrm{Li}^{+} @ \mathrm{C}_{60}{ }^{\circ}-$ radicals are involved in the magnetic reactions. Fitting the $\left(\chi-\chi_{0}\right)^{-1}$ to the Curie-Weiss law at high temperatures $(T>175 \mathrm{~K})$ yields a large negative Curie-Weiss temperature, $\theta_{\mathrm{cw}}=-190 \mathrm{~K}$, suggesting strong antiferromagnetic $(\mathrm{AF})$ interactions between the spins $\left(\chi_{0}\right.$ is defined as core diamagnetic or Van-Vleck paramagnetic susceptibility ${ }^{44}$ and determined to be $8.8 \times 10^{-4} \mathrm{~cm}^{3} \mathrm{~mol}^{-1}$ in Supporting Information Fig. 7). Even the fitted low-temperature $\chi^{-1}(T=1.8-10 \mathrm{~K})$ results in a $\theta_{\mathrm{cw}}=-1.6 \mathrm{~K}$, indicating significant $\mathrm{AF}$ interactions. The $\left(\chi-\chi_{0}\right) T$ value at $300 \mathrm{~K}$ is $1.71 \mathrm{~cm}^{3} \mathrm{~K} \mathrm{~mol}^{-1}$ (Supporting Information Fig. 8), which follows the theoretical prediction of four $\mathrm{Cu}^{2+}$ ions and one $\mathrm{Li}^{+} @ \mathrm{C}_{60}{ }^{-}-$radical per unit $\left(\chi T_{\text {calc }}=0.375\right.$ $\left.\times 5=1.875 \mathrm{~cm}^{3} \mathrm{~K} \mathrm{~mol}^{-1}\right)$. The rapid decrease in $\left(\chi-\chi_{0}\right) T$ with temperature reduction indicates that $\mathrm{AF}$ exchange interactions are dominant. In addition, the magnetic-field dependence of magnetisation from 1.8 to $300 \mathrm{~K}$ does not show any visible hysteresis loops (Fig. 4b).

To elucidate such strong exchange coupling in $\mathbf{1}$, we consider Fig. 4c, which shows the spin arrangements in a ladder-like structure with four $\mathrm{Cu}^{2+}$ ions positioned at the corner of the rectangular plane and one $\mathrm{Li}^{+} @ \mathrm{C}_{60}{ }^{-}$at the centre. In this magnetic pattern, owing to symmetry, one $\mathrm{Cu}^{2+}$ ion magnetically interacts with three adjacent $\mathrm{Cu}^{2+}$ ions $\left(J_{12}\right.$ and $\left.J_{13}\right)$, which are magnetically linked by the $\mathrm{Li}^{+} @ \mathrm{C}_{60}{ }^{--}$radicals. Moreover, the $\mathrm{Cu}^{2+}$ ions interact with $\mathrm{Li}^{+} @ \mathrm{C}_{60}^{--}\left(J_{\mathrm{Cu}-\mathrm{C}_{60}^{-}}\right)$via $\mathrm{Cu}-\mathrm{C}$ bonds. Such complicated and competitive interactions lead to a magnetically frustrated ground state. To obtain the $J$ values, we used the following spin Hamiltonian $\hat{H}$ using Eq. 1 by considering two kinds of exchange coupling $J_{\mathrm{Cu}-\mathrm{Cu}}$ and $J_{\mathrm{Cu}-\mathrm{C}_{60}^{-}}$.

$$
\begin{aligned}
\hat{H}= & -2 J_{\mathrm{Cu}-\mathrm{Cu}}\left(\hat{\mathbf{s}}_{\mathrm{Cu} 1} \cdot \hat{\mathbf{s}}_{\mathrm{Cu} 2}+\hat{\mathbf{s}}_{\mathrm{Cu} 3} \cdot \hat{\mathbf{s}}_{\mathrm{Cu} 4}\right) \\
& -2 J_{\mathrm{Cu}-\mathrm{C}_{60}^{-}}\left(\hat{\mathbf{s}}_{\mathrm{Cu} 1} \cdot \hat{\mathbf{s}}_{\mathrm{C}_{60}^{-}}+\hat{\mathbf{s}}_{\mathrm{Cu} 2} \cdot \hat{\mathbf{s}}_{\mathrm{C}_{60}^{-}}+\hat{\mathbf{s}}_{\mathrm{Cu} 3} \cdot \hat{\mathbf{s}}_{\mathrm{C}_{60}^{--}}+\hat{\mathbf{s}}_{\mathrm{Cu} 4} \cdot \hat{\mathbf{S}}_{\mathrm{C}_{60}^{--}}\right) \\
& +\mu_{B} \overline{\mathbf{B}} \cdot g_{\mathrm{Cu}} \cdot \hat{\mathbf{s}}_{\mathrm{Cu}}+\mu_{B} \cdot g_{\mathrm{C}_{60}^{-}} \cdot \overline{\mathbf{B}} \cdot \hat{\mathbf{s}}_{\mathrm{C}_{60}^{-}}
\end{aligned}
$$

To avoid overparameterization, we assumed the interactions of $J_{14}$ and $J_{23}$ are ignored compared to $J_{12}, J_{34}$ and $J_{\mathrm{Cu}-\mathrm{C}_{60}^{--}}$due to their long metal-metal distances and the interactions between $\mathrm{C}_{60}{ }^{\circ-}$ and $\mathrm{Cu} 1, \mathrm{Cu} 2$ are equivalent. The effective exchange coupling parameters of $J_{\mathrm{Cu}-\mathrm{Cu}}=-170(5) \mathrm{K}$ and $J_{1-\mathrm{C}_{60}^{-}}=$ $J_{2-\mathrm{C}_{60}^{-}}=-185(3) \mathrm{K}$ with $g_{\mathrm{Cu}}=2.09(0)$ were obtained after the best fit $\left(g_{\mathrm{C} 60^{\circ}}-\right.$ was fixed to 2.0). The negative $J_{\mathrm{Cu}-\mathrm{Cu}}$ and $J_{\mathrm{Cu}-\mathrm{C}_{60}^{-}}$ values confirm that any two neighbouring spins are AF coupled. Therefore, in this rectangular spin-lattice, composed of several triangular lattices (such as $\Delta \mathrm{Cu}_{1} \mathrm{Cu}_{2} \mathrm{C}_{60^{\circ}}{ }^{-}$), we can observe the three spins exhibiting competing interactions. Frustration 
a)

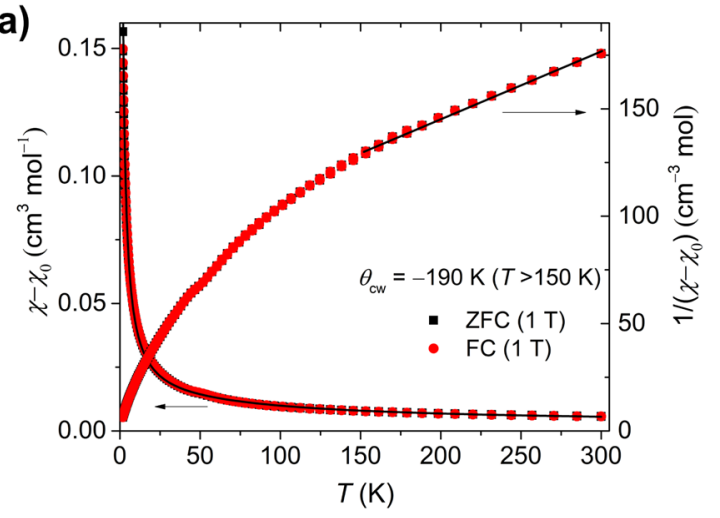

b)

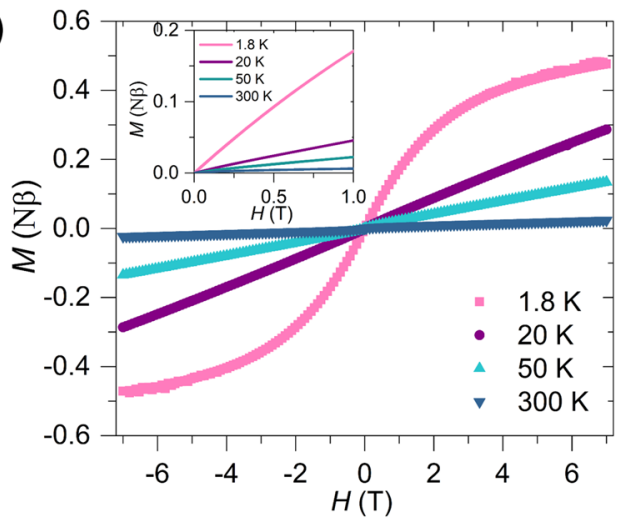

c)

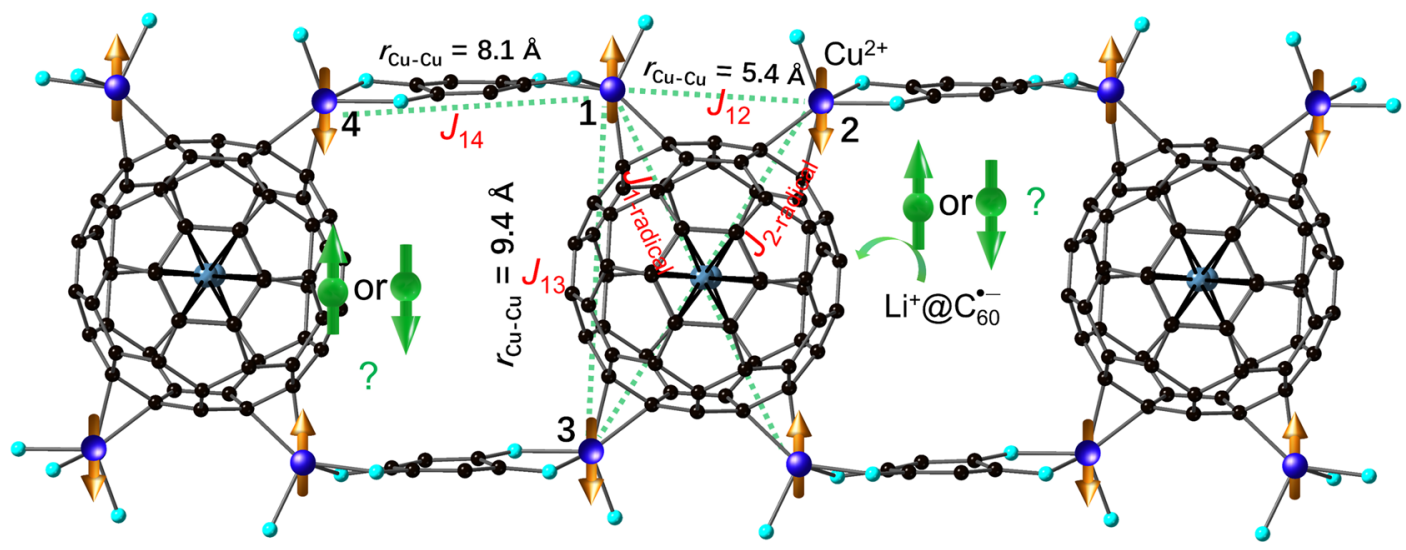

Fig. 4 Magnetic properties. a The temperature dependence of magnetic susceptibility product $\left(\chi-\chi_{0}\right)$ of $\mathbf{1}$ in FC, ZFC modes and the corresponding $\left(\chi-\chi_{0}\right)^{-1}-T$ plots under a $1 \mathrm{~T}$ field from 1.8 to $300 \mathrm{~K}$. The black curve represents the best fit for $\left(\chi-\chi_{0}\right)$ by considering the possible exchange interaction between spins. The black line represents the best fit by the Curie-Weiss law. A large negative $\theta_{\mathrm{cw}}=-190 \mathrm{~K}$ is observed, suggesting strong AF exchange interactions. b Magnetic-field dependence of magnetisation of $\mathbf{1}$ at 1.8, 20,50, and $300 \mathrm{~K}$. There is no hysteresis loop at these temperatures. c Spin orientations of the $\mathrm{Cu}^{2+}$ ions and $\mathrm{Li}^{+} @ \mathrm{C}_{60}{ }^{--}$superatoms emerging in the 1D ladder-like magnetic chain; the four $\mathrm{Cu}$ ions and $\mathrm{Li}^{+} @ \mathrm{C}_{60}{ }^{\bullet-}$ superatoms are aligned in a triangular-like lattice and antiferromagnetically interact with each other.

parameter $45=\left|\theta_{\mathrm{cw}}\right| / T_{\mathrm{N}}$ is $>105\left(T_{\mathrm{N}}<1.8 \mathrm{~K}\right)$, indicating that 1 has a highly frustrated ground state. In addition, the real-part alternating current magnetic susceptibility $\left(\chi^{\prime}\right)$ measurements indicated the absence of magnetic ordering to $1.8 \mathrm{~K}$ (Supporting Information Fig. 9). Such a frustrated lattice leads to inner $\mathrm{Li}^{+}$ ions locating far away from the four coordinated $\mathrm{Cu}^{2+}$ ions. Moreover, because of the pull forces from the eight external $\mathrm{Cu}-\mathrm{C}$ bonds and six internal $\mathrm{Li}-\mathrm{C}$ bonds, the $\mathrm{Li}^{+} @ \mathrm{C}_{60}$ cage is geometrically distorted with the diagonal lengths of 6.4 and $7.1 \AA$ A, respectively (Supporting Information Fig. 10).

Heat capacity and electrical conductivity. To further demonstrate the absence of magnetic phase transitions, the temperature dependence of heat capacity $(C)$ was measured. The $C$ versus $T$ and $C / T$ versus $T$ plots (Fig. $5 \mathrm{a}, \mathrm{b}$ ) clearly showed that there is no sharp thermal anomaly in $2-20 \mathrm{~K}$, indicative of no magnetic ordering in this temperature range. Usually, heat capacity is mathematically expressed as $C=\gamma T+\beta T^{3}$, where the $\gamma T$ and $\beta T^{3}$ terms are relevant to the density of state and crystal lattice, respectively. The data at low temperatures below $7 \mathrm{~K}$, shown in Fig. $5 c$, clearly manifests the existence of a linearly temperaturedependent term (the $\gamma$ term) despite the semiconducting ground state. The magnitude of $\gamma$ in $2-7 \mathrm{~K}$ is estimated at $12 \pm 2 \mathrm{~mJ} \mathrm{~K}^{-2}$ $\mathrm{mol}^{-1}$ from the linear extrapolation of the $C / T$ versus $T^{2}$ plot down to zero $\mathrm{K}$. This finite $\gamma$ value was reported in organic $2 \mathrm{D}$ triangular $\kappa$-(BEDT-TTF $)_{2} \mathrm{Cu}_{2}(\mathrm{CN})_{3}$ and inorganic honeycomb $\mathrm{H}_{3} \mathrm{LiIr}_{2} \mathrm{O}_{6}$ QSLs $^{32,46}$, suggesting possible QSL state of $\mathbf{1}$. In addition, the black colour of the single-crystals with metallic surfaces indicates that 1 could be electrically conductive. Figure $5 \mathrm{~d}$ shows the temperature dependence of $\sigma$ in the range of 250-300 K, obtained with a two-probe dc method. The $\sigma$ value at $300 \mathrm{~K}$ is $(4.4-8.2) \times 10^{-5} \mathrm{~S} \mathrm{~cm}^{-1}$ based on measuring several single-crystals. Parameter $\sigma$ decreases with temperature reduction, indicating that $\mathbf{1}$ behaves as a semiconductor. The activation energy $\left(E_{\mathrm{a}}\right)$ is determined to be $0.44 \mathrm{eV}$ by using the Arrhenius function.

Using generalised charge decomposition analysis (GCDA) method to understand donor-acceptor bonded interactions. To further elucidate the electronic ground states, we first calculated the orbital energy for $\mathrm{Cu}_{2}(\mathrm{~L})(\mathrm{py})_{4}$ using the TD-DFT method. The calculated absorption spectrum coincides with the experimental data in the range of 300-1500 nm (Supporting Information Fig. 11 and Supporting Information Table 1). The strong absorption band at $920 \mathrm{~nm}(1.35 \mathrm{eV})$ is $100 \%$ attributed to ET from the HOMO (Fig. 6a) to LUMO (Fig. 6b). The electrons are predominantly located at both terminal $\mathrm{Cu}$ ions and the central ligand in the HOMO. Our calculations showed strong hybridisation with $58 \% d_{x z}(\mathrm{Cu})$ electron density and $25 \% p_{z}(\mathrm{~N})$ electron densities, thus indicating that the electrons are delocalised in HOMO. Thus, the electron-intensive $d_{x z}(\mathrm{Cu})$ orbitals are highly capable of donating electrons to the $\mathrm{Li}^{+} @ \mathrm{C}_{60}$ cage through $\mathrm{Cu}-\mathrm{C}$ bonds. The higher energy absorption band at $443 \mathrm{~nm}(2.80 \mathrm{eV})$ calculated at $402 \mathrm{~nm}(3.08 \mathrm{eV})$ is $78 \%$ assigned to ET from $\mathrm{HOMO}-1$ to LUMO +1 (Supporting Information Fig. 12). 
a)

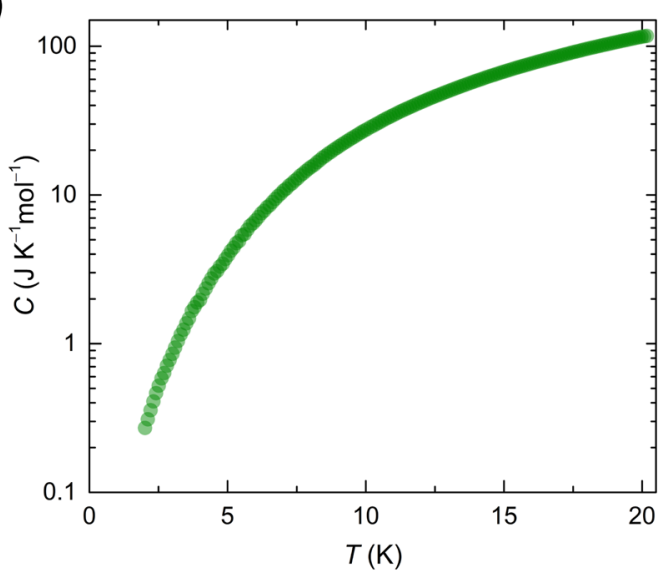

c)

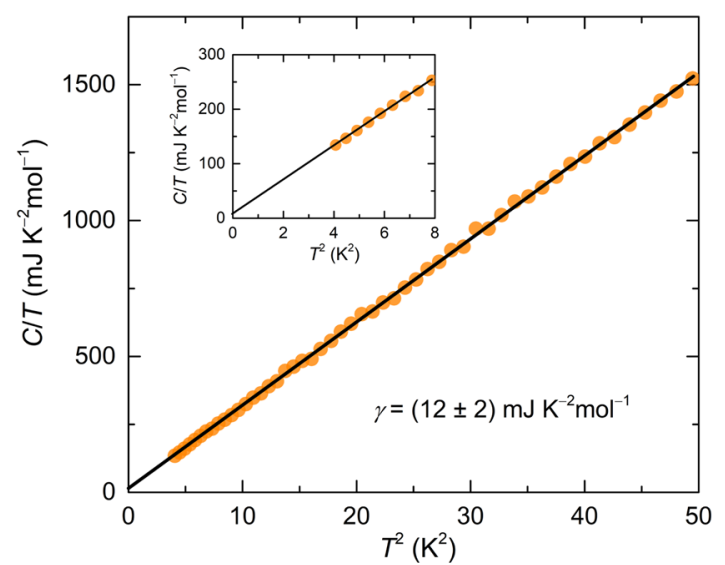

b)

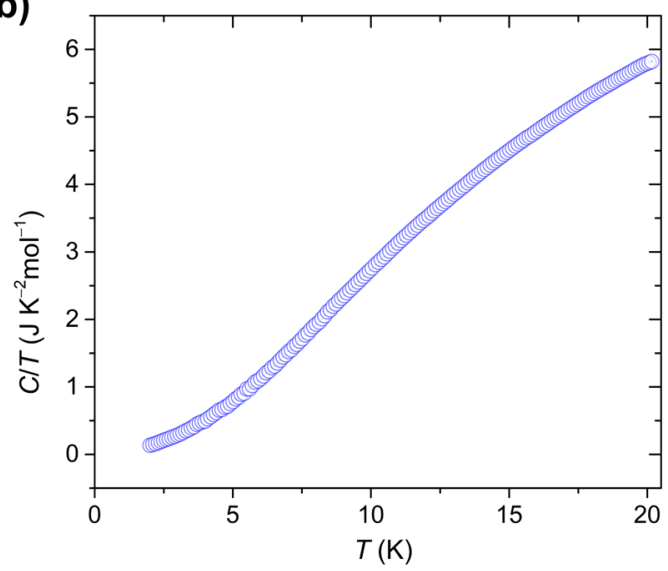

d)

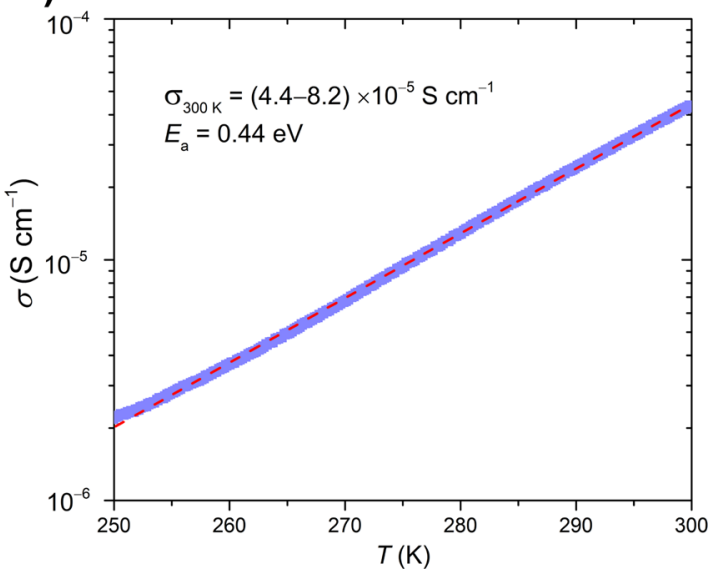

Fig. 5 Heat capacity and temperature dependence of $\sigma$ of 1. a Temperature dependence of the total heat capacity (C) in the Trange of 2.0-20 K in zero fields. b $C / T$ vs $T$ plot. c $C / T$ vs $T^{2}$ plot. d The Temperature dependence of $\sigma$ for single-crystals obtained by using a two-probe method in the range of $250-300 \mathrm{~K}$.

To better understand the $\mathrm{D}-\mathrm{A}$ bonding interactions, we used GCDA to investigate the electron-transfer amounts from $\mathrm{Cu}_{2} \mathrm{~L}(\mathrm{py})_{3}$ (by adding a pyridine molecule to the $\mathrm{Cu}_{2} \mathrm{~L}(\mathrm{py})_{2}$ molecule) to the $\mathrm{Li}$ $+@ \mathrm{C}_{60}$ cage and the generation of complex orbitals by the fragments molecular orbitals in such an open-shell system. Figure $6 c, d$ shows the calculated $\alpha$ and $\beta$ forms of the orbital interaction diagrams for the triplet $\mathrm{Cu}_{2} \mathrm{~L}(\text { py })_{3} \mathrm{Li}^{+} @ \mathrm{C}_{60}$ complex, respectively. The $\left[\mathrm{Cu}_{2} \mathrm{~L}(\mathrm{py})_{3}\right]^{+}$fragment was assumed to be a doublet with a positive charge, and the other fragment $\left(\mathrm{Li}^{+} @ \mathrm{C}_{60}{ }^{-}-\right)$ contained an anionic radical in the $\mathrm{C}_{60}$ cage (doublet). We calculated the net CT value as $0.275 e^{-}$(Supporting Information Table 2) by estimating the difference between electron donation and back-donation between the fragments. The partial CT interactions can be understood as follows: each $\mathrm{Cu}_{2}(\mathrm{~L})(\mathrm{py})_{3}$ can only transfer $0.25 e^{-}$to the $\mathrm{Li}^{+} @ \mathrm{C}_{60}$ cage as the $\mathrm{Li}^{+} @ \mathrm{C}_{60}$ cage is coordinated with four $\mathrm{Cu}_{2}(\mathrm{~L})(\mathrm{py})_{2}$. Thus, the GCDA calculation shows good agreement with the $\mathrm{CV}$ and magnetic results. From Fig. $6 \mathrm{c}$, we note that the HOMO and LUMO of the complex are quite similar with an energy gap of $0.40 \mathrm{eV}$ in the $\alpha$ form. The small bandgap is due to the significant contributions from HOMO of $\mathrm{Li}^{+} @ \mathrm{C}_{60}$ and LUMO of $\mathrm{Cu}_{2}(\mathrm{~L})(\mathrm{py})_{3}$. The electron densities are mainly observed on the central ligand and the $\mathrm{Li}^{+} @ \mathrm{C}_{60}$ cage. The HOMO of the complex originates from the mixture of $45 \%$ LUMO of $\mathrm{Cu}_{2} \mathrm{~L}(\mathrm{py})_{3}$ and $32 \%$ HOMO and $21 \%$ LUMO of $\mathrm{Li}^{+} @ \mathrm{C}_{60}$; similarly, the LUMO is mixed with 52\% $\mathrm{Cu}_{2} \mathrm{~L}(\mathrm{py})_{3} \mathrm{LUMO}, 33 \% \mathrm{Li}^{+} @ \mathrm{C}_{60} \mathrm{HOMO}$, and $12 \% \mathrm{Li}^{+} @ \mathrm{C}_{60}$ LUMO. This result indicates that the electrons in the complex's $\mathrm{HOMO}$ are solely derived from the $\mathrm{HOMO}$ of $\mathrm{Li}^{+} @ \mathrm{C}_{60}$; there is no electron contribution from the occupied $\mathrm{Cu}_{2} \mathrm{~L}(\text { py })_{3}$ orbitals. Therefore, the complex's orbitals are not strongly mixed by fragments in the $\alpha$ form. In contrast, $\beta$ electrons exhibit a deeper frontier orbital toward a electrons, indicating that $\beta$ electrons are more electronically stable. Figure $6 \mathrm{~d}$ shows that the frontier occupied orbitals of the complex in $\beta$ form are doubly degenerated, indicating the significant contributions of fullerene orbitals. The electrons in the complex's HOMO are mainly delocalised on the $\mathrm{Li}^{+} @ \mathrm{C}_{60}$ cage and a small fraction in the $d_{X Z}$ orbital of $\mathrm{Cu}$ ions, and these electrons originate from 11\% $\mathrm{HOMO}$, 4\% HOMO-1 (Supporting Information Fig. 13), 2\% HOMO-2 (Supporting Information Fig. 14) of $\mathrm{Cu}_{2} \mathrm{~L}(\mathrm{py})_{3}, 29 \% \mathrm{HOMO}, 5 \%$ HOMO-1 (Supporting Information Fig. 15), and 42\% HOMO-3 of $\mathrm{Li}^{+} @ \mathrm{C}_{60}$. It is worth noting that a large number of delocalised $d_{X Z}$ electrons of $\mathrm{Cu}$ ions were observed in the HOMO of $\mathrm{Cu}_{2} \mathrm{~L}(\mathrm{py})_{3}$; however, the number diminished in the complex's HOMO. This result strongly suggests that electrons transferred from $\mathrm{Cu}_{2} \mathrm{~L}(\mathrm{py})_{3}$ to the $\mathrm{Li}^{+} @ \mathrm{C}_{60}$ cage once $\mathrm{Cu}-\mathrm{C}$ bonds were established. Thus, the bandgap is expected to be small because the orbital interactions between the fragments are strong. However, the calculated bandgap $(\Delta E=1.17 \mathrm{eV})$ is only slightly smaller than that of undoped $\mathrm{Li}^{+} @ \mathrm{C}_{60}(\Delta E \sim 1.5 \mathrm{eV})$, which is probably caused by the strong onsite Coulomb interactions.

In summary, we succeeded in observing a conductive metalfullerene-bonded framework with strong spin frustration, constructed by using redox-active $\mathrm{Cu}_{2}(\mathrm{~L})(\mathrm{py})_{4}$ and $\mathrm{Li}^{+} @ \mathrm{C} 60$ molecules. Via the precise control of the redox activities in each 

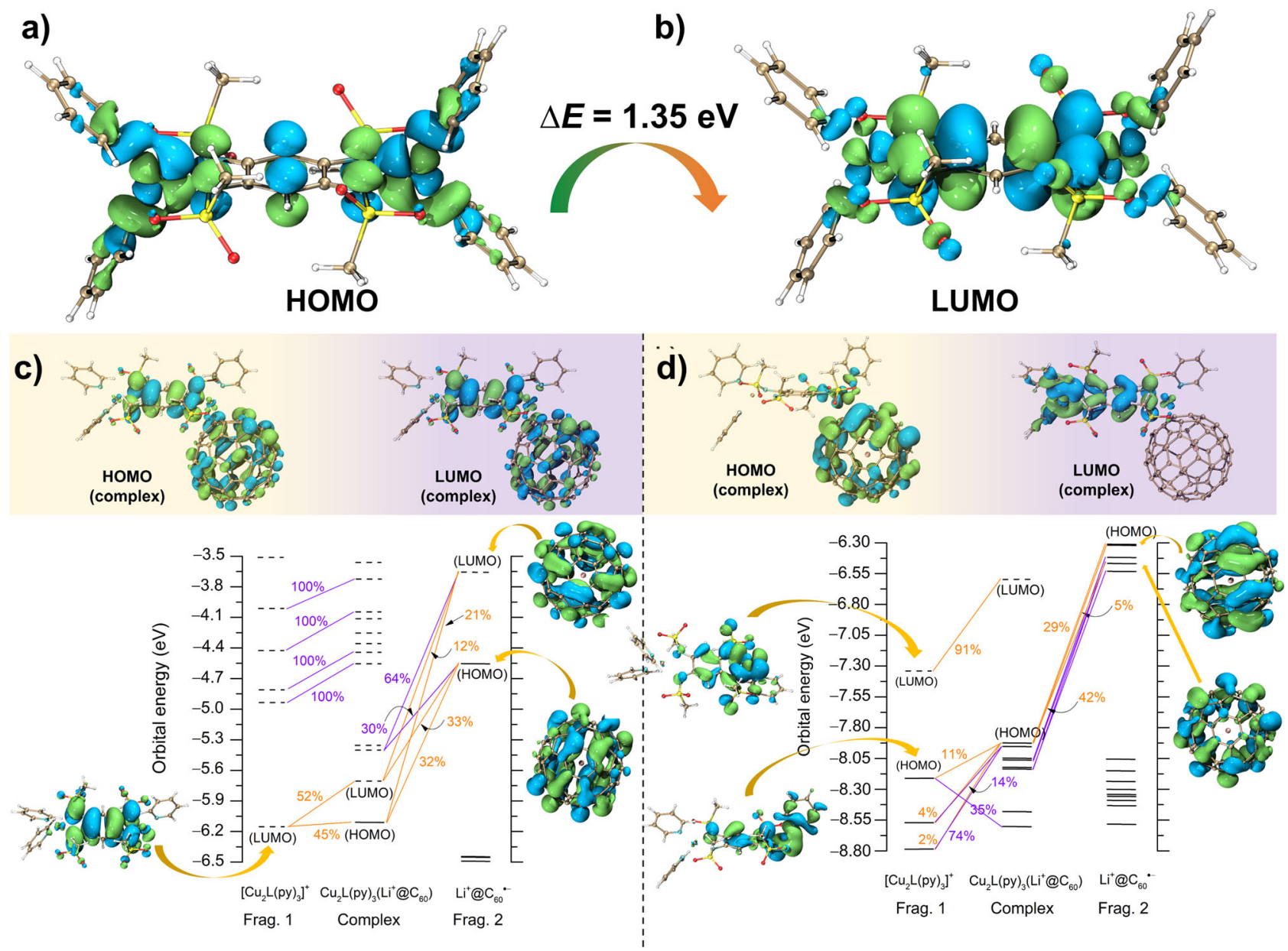

Fig. 6 Orbital calculations and generalised charge decomposition analysis (GCDA) for donor-acceptor bonded interactions. a $\mathrm{HOMO}$ of $\mathrm{Cu}_{2}(\mathrm{~L})(\mathrm{py})_{4}$. b LUMO of $\mathrm{Cu}_{2}(\mathrm{~L})(\mathrm{py})_{4}$. c Orbital interaction diagram and molecular orbitals in $\alpha$ electron form. $\mathbf{d}$ Orbital interaction diagram and molecular orbitals in $\beta$ electron form. The black solid lines and dotted lines represent the occupied and virtual orbitals, respectively. The orange and violet lines represent the contribution to the HOMO and LUMO and other orbitals, respectively. The isovalue for the electrons is set at 0.02 .

species, the chemical bonds between the dinuclear electronic donor and the 3D spherical $\mathrm{Li}^{+} @ \mathrm{C}_{60}$ acceptor allow for an interesting $S=1 / 2$ spin-lattice in a $1 \mathrm{D}$ ladder-like magnetic chain. The metal-fullerene bond accompanied by CT leads to a strong spin frustration ground state. Such a heterospin system is promising for the development of high-performance moleculebased spintronic devices and can aid in exploring new QSL candidates. Further studies in this direction aim to control the spin dynamics in a triangular or kagomé network using $\mathrm{Li}^{+} @ \mathrm{C}_{60}$ superatoms.

\section{Methods}

Experimental synthesis. A pure form of $\left(\mathrm{Li}^{+} @ \mathrm{C}_{60}\right)\left(\mathrm{NTf}_{2}{ }^{-}\right)$was obtained from Idea International Co., Ltd. Sendai, Japan. $\left(\mathrm{Li}^{+} @ \mathrm{C}_{60}\right)\left(\mathrm{NTf}_{2}{ }^{-}\right)$was synthesised by anion exchange from $\left(\mathrm{Li}^{+} @ \mathrm{C}_{60}\right)\left(\mathrm{PF}_{6}{ }^{-}\right)$. Typically, $\left.\mathrm{Li}^{+} @ \mathrm{C}_{60}\right)\left(\mathrm{PF}_{6}{ }^{-}\right)(10 \mathrm{mg}$, $0.0115 \mathrm{mmol}$ ) and $\operatorname{LiNTf}_{2}(5.0 \mathrm{mg}, 0.0174 \mathrm{mmol})$ dissolved in $2.5 \mathrm{~mL}$ dichloromethane (DCM) and then sonicated 10 minutes to give a purple suspension. The suspension was filtered and the resulting clean solution was diffused by diethyl ether at $3{ }^{\circ} \mathrm{C}$ for 3 days to produce black solids. The solids were washed with a small amount of DCM and dried at room temperature (Yield: quantitative).

Synthesis of ligand $\left(\mathrm{H}_{4} \mathrm{~L}=1,2,4,5\right.$-tetrakis(methanesulfonamido)benzene). $\mathrm{H}_{4} \mathrm{~L}$ was synthesised from the reaction of 1,2,4,5-tetraaminobenzene $(138.2 \mathrm{mg}$, $1.0 \mathrm{mmol}$ ) and methylsulfonyl chloride $(458.3 \mathrm{mg}, 4.0 \mathrm{mmol})$ in $40 \mathrm{~mL}$ pyridine, and the resulting dark brown solution was stirred continuously for $3 \mathrm{~h}$ and then quenched in $15 \%$ aq. $\mathrm{HCl}$. The resulting pale brown solid was collected by filtration, washed with distilled water $(2 \times 10 \mathrm{~mL})$, and dried at $80^{\circ} \mathrm{C}$ overnight (yield: $321 \mathrm{mg}, 72 \%$ ). IR in attenuated total reflection (ATR) mode: $v(\mathrm{~N}-\mathrm{H})=3250 \mathrm{~cm}^{-1} ; v\left(\mathrm{CH}_{3}\right)=2933 \mathrm{~cm}^{-1} ; v(\mathrm{~S}=\mathrm{O})=1142 \mathrm{~cm}^{-1}$.
Synthesis of $\mathrm{Cu}_{2}(\mathrm{~L})(\mathrm{py})_{4}$. Cu(acetate $)_{2}$ solid $(363.3 \mathrm{mg}, 2.0 \mathrm{mmol})$ was slowly added to $10 \mathrm{~mL} \mathrm{H}_{4} \mathrm{~L}\left(446.5 \mathrm{mg}, 1.0 \mathrm{mmol}\right.$ ) pyridine solution under dry $\mathrm{N}_{2}$ gas. The resulting pale brown suspension immediately turned into a clear deep-blue solution, which was subsequently stirred for $12 \mathrm{~h}$. Black block-like crystals were obtained by diethyl ether slowly diffused into the above solution (yield: $717.6 \mathrm{mg}$, $81 \%)$. The crystal structure was determined via single-crystal X-ray diffraction analysis. The purity was confirmed by CHN analysis (Supporting Information Table 3) and PXRD pattern (Supporting Information Fig. 16).

Synthesis of $\left\{\left[\mathrm{Cu}_{4}\left(\mathrm{Li}^{+} @ \mathrm{C}_{60}\right)(\mathrm{L})(\mathrm{py})_{4}\right]\left(\mathrm{NTf}_{2}\right)\right.$ (hexane $\left.)\right\}_{n}(\mathbf{1})$. This experiment was conducted in an argon-filled glovebox. First, $\left(\mathrm{Li}^{+} @ \mathrm{C}_{60}\right)\left(\mathrm{NTf}_{2}{ }^{-}\right)(1.0 \mathrm{mg}$, $0.001 \mathrm{mmol}$ ) was dissolved in $1 \mathrm{~mL}$ dry $o$-DCB, and the resulting pink solution was slowly added to $\mathrm{Cu}_{2}(\mathrm{~L})(\mathrm{py})_{4}(1.8 \mathrm{mg}, 0.002 \mathrm{mmol})$ in $10.0 \mathrm{~mL} o$-DCB solution. The molar ratio between $\left(\mathrm{Li}^{+} @ \mathrm{C}_{60}\right)\left(\mathrm{NTf}_{2}{ }^{-}\right)$and $\mathrm{Cu}_{2}(\mathrm{~L})(\mathrm{py})_{4}$ was 1:2. The mixture solution immediately turned dark brown. It was stirred for $3 \mathrm{~h}$, after which the solution was filtered. Small shiny black crystals with a typical size of $0.04 \times 0.01 \times$ $0.001 \mathrm{~cm}$ were obtained by slow diffusion with hexane in one week (yield: $1.0 \mathrm{mg}$, $33 \%$ ). The purity was confirmed by $\mathrm{CHN}$ analysis (Supporting Information Table 2) and PXRD pattern (Supporting Information Fig. 17).

Physical characterisation. Single-crystal crystallographic data (exp_860) were collected at $120 \mathrm{~K}$ using a Rigaku Saturn 70 CCD diffractometer (Rigaku, Tokyo, Japan) with graphite monochromated Mo Ka radiation $(\lambda=0.71073 \AA)$ generated by a VariMax microfocus X-ray rotating anode source. The single-crystal X-ray diffractions were measured at additional temperature points at 25,50,100,200, and $300 \mathrm{~K}$ by using synchrotron radiation at Spring-8, Japan. The structures were solved by using Olex 2 software ${ }^{47}$. Cyclic voltammetry $(\mathrm{CV})$ was performed using an ALS/HCH Model 620D electrochemical analyser. A glassy carbon (3 mm diameter) electrode was used as the working electrode, a Pt wire was used as the counter electrode, and an $\mathrm{Ag} / \mathrm{Ag}^{+}$was used as the reference electrode. The supporting electrolyte was $0.1 \mathrm{M}$ tetrabutylammonium hexafluorophosphate $\left(\mathrm{TBA} \cdot \mathrm{PF}_{6}\right)$ in dry $o$-DCB. The solid-state absorption spectra were acquired by 
compound $\mathbf{1}$ was embedded in $\mathrm{KBr}$ pellets with the use of a Shimadzu UV-3100PC instrument, and subsequently, the pellets were inserted into a transparent sealed cell and protected by argon gas. The solution-state absorption spectra were measured in a sealed plate tube filled with argon gas. The temperature dependence of the solid-state EPR spectra was examined by using the JEOL JES-FA100 device. Magnetic susceptibility measurements were conducted on a polycrystalline sample using a Quantum Design SQUID magnetometer (MPMS-7L). The magnetic susceptibility data were fitted by PHI software ${ }^{48}$. The temperature dependence of heat capacity was measured by using the Quantum Design PPMS. The temperature dependence of $\sigma$ was measured on single-crystals via a two-probe method by using the Quantum Design PPMS 6000 instrument.

Quantum chemical calculation. Geometry optimisation was performed by using density-functional theory (DFT) at the B3LYP/6-31G(d, p) level for pristine $\mathrm{Cu}_{2}(\mathrm{~L})$ (py) $)_{4}$. The absorption spectrum was calculated for the optimised geometry by using the TD-DFT method at the CAM-B3LYP/def2TZVP level. The $\mathrm{Cu}_{2}(\mathrm{~L})(\mathrm{py})_{3}(\mathrm{Li}$ $+\mathrm{C}_{60}$ ) complex was cut from the X-ray structure by adding one pyridine molecule as the terminal ligand, and the resulting structure was optimised by applying DFT at the UB3LYP/6-31G(d,p) level. The optimised structure was decomposed into two fragments, $\left[\mathrm{Cu}_{2}(\mathrm{~L})(\mathrm{py})_{3}\right]^{+}$and $\mathrm{Li}^{+} @ \mathrm{C}_{60}{ }^{-}$, for single-point calculation. The $\mathrm{GCDA}^{49}$ was used for the open-shell form of this complex and the two fragments by applying DFT at the UB3LYP/def2tzvp level. All calculations were performed using Gaussian 16 software $^{50}$, and the output results were analysed using the Multiwfn programme $e^{49,51}$

\section{Data availability}

The crystallographic data generated in this study have been deposited in the CCDC database under accession codes 2039740 (compound $\mathbf{1}$ at $120 \mathrm{~K}$ ), $2039286\left(\mathrm{Cu}_{2}(\mathrm{~L})(\mathrm{py})_{4}\right.$ at $120 \mathrm{~K}$ ), and 2121505-2121509 (compound $\mathbf{1}$ at 25, 50, 100, 200, and $300 \mathrm{~K}$ ). The data generated in this manuscript are available within the manuscript, its supplementary information, or from the authors upon request.

Received: 9 July 2021; Accepted: 11 January 2022;

Published online: 25 January 2022

\section{References}

1. Aoyagi, S. et al. A layered ionic crystal of polar $\mathrm{Li}_{0} \mathrm{C}_{60}$ superatoms. Nat. Chem. 2, 678-683 (2010)

2. Stasyuk, A. J., Stasyuk, O. A., Solà, M. \& Voityuk, A. A. Hypsochromic solvent shift of the charge separation band in ionic donor-acceptor $\mathrm{Li}^{+} @ \mathrm{C}_{60} \subset[10]$ CPP. Chem. Commun. 55, 11195-11198 (2019).

3. Yamada, M., Ohkubo, K., Shionoya, M. \& Fukuzumi, S. Photoinduced electron transfer in a charge-transfer complex formed between corannulene and $\mathrm{Li}^{+} @ \mathrm{C}_{60}$ by concave-convex $\pi-\pi$ interactions. J. Am. Chem. Soc. 136, 13240-13248 (2014).

4. Rehman, H. U., McKee, N. A. \& McKee, M. L. Saturn systems. J. Comput. Chem. 37, 194-209 (2016).

5. Stasyuk, A. J., Stasyuk, O. A., Sola, M. \& Voityuk, A. A. Hypsochromic solvent shift of the charge separation band in ionic donor-acceptor $\mathrm{Li}^{+} @ \mathrm{C}_{60}$ subset of 10$]$ CPP. Chem. Commun. 55, 11195-11198 (2019).

6. Gonzalez-Veloso, I., Rodriguez-Otero, J. \& Cabaleiro-Lago, E. M. Endohedral alkali cations promote charge transfer transitions in complexes of $\mathrm{C}_{60}$ with [10]cycloparaphenylenes. Phys. Chem. Chem. Phys. 21, 16665-16675 (2019).

7. Watanabe, T. et al. Iridium and platinum complexes of $\mathrm{Li}^{+} @ \mathrm{C}_{60}$. Organometallics 33, 608-611 (2013).

8. Jeon, I. et al. Lithium-ion endohedral fullerene $\left(\mathrm{Li}^{+} @ \mathrm{C}_{60}\right)$ dopants in stable perovskite solar cells induce instant doping and anti-oxidation. Angew. Chem. Int. Ed 57, 4607-4611 (2018).

9. Chandler, H. J., Stefanou, M., Campbell, E. E. B. \& Schaub, R. Li@ $\mathrm{C}_{60}$ as a multi-state molecular switch. Nat. Commun. 10, 2283 (2019).

10. Krawez, N., Gromov, A., Buttke, K. \& Campbell, E. E. B. Thermal stability of Li@C 60 . Eur. Phys. J. D. 9, 345-349 (1999).

11. Bernshtein, V. \& Oref, I. Surface migrations of endohedral $\mathrm{Li}^{+}$on the inner wall of $\mathrm{C}_{60}$. Phys. Rev. A. 62, 033201 (2000).

12. Lu, X., Feng, L., Akasaka, T. \& Nagase, S. Current status and future developments of endohedral metallofullerenes. Chem. Soc. Rev. 41, 7723-7760 (2012).

13. Aoyagi, $\mathrm{S}$. et al. Rock-salt-type crystal of thermally contracted $\mathrm{C}_{60}$ with encapsulated lithium cation. Angew. Chem. Int. Ed. 51, 3377-3381 (2012).

14. Lee, C. H. et al. Ferromagnetic ordering in superatomic solids. J. Am. Chem. Soc. 136, 16926-16931 (2014).

15. Hebard, A. F. et al. Superconductivity at $18 \mathrm{~K}$ in potassium-doped $\mathrm{C}_{60}$. Nature 350, 600-601 (1991).

16. Tanigaki, K. et al. Superconductivity at $33 \mathrm{~K}$ in $\mathrm{Cs}_{x} \mathrm{Rb}_{y} \mathrm{C}_{60}$. Nature 352, 222-223 (1991).
17. Hebard, A. F. Superconductivity in doped fullerenes. Phys. Today. 45, 26-32 (1992).

18. Ganin, A. Y. et al. Bulk superconductivity at $38 \mathrm{~K}$ in a molecular system. Nat. Mater. 7, 367-371 (2008).

19. Mulliken, R. S. Molecular compounds and their spectra. II. J. Am. Chem. Soc 74, 811-824 (1952).

20. Foster, R. Organic Charge-Transfer Complexes (Academic Press, New York, 1969).

21. Mulliken, R. S. P \& Person, W. B. Molecular Complexes, A Lecture And Reprint Volume (Wiley-Interscience, New York, 1969).

22. Fukuzumi, S., Wong, C. L. \& Kochi, J. K. Unified view of Marcus electron transfer and Mulliken charge transfer theories in organometallic chemistrysteric effects in alkylmetals as quantitative probes for outer-sphere and innersphere mechanisms. J. Am. Chem. Soc. 102, 2928-2939 (1980).

23. Canevet, D. et al. Macrocyclic hosts for fullerenes: Extreme changes in binding abilities with small structural variations. J. Am. Chem. Soc. 133, 3184-3190 (2011).

24. Canevet, D., Perez, E. M. \& Martin, N. Wraparound hosts for fullerenes: Tailored macrocycles and cages. Angew. Chem. Int. Ed. 50, 9248-9259 (2011).

25. Otsuka, A. et al. Design of spin-frustrated monomer-type $\mathrm{C}_{60^{-}}{ }^{-}$Mott insulator. Crystals 8, 115 (2018).

26. Li, W. M. et al. Superconductivity in a unique type of copper oxide. Proc. Natl. Acad. Sci. USA 116, 12156-12160 (2019).

27. Jerome, D., Mazaud, A., Ribault, M. \& Bechgaard, K. Superconductivity in a synthetic organic conductor (TMTSF) ${ }_{2} \mathrm{PF}_{6}$. Cr. Acad. Sci. B. Phys. 290, 27-30 (1980).

28. Oshima, K., Urayama, H., Yamochi, H. \& Saito, G. A new ambient pressure organic superconductor (BEDT-TTF $)_{2} \mathrm{Cu}(\mathrm{NCS})_{2}$ with Tc above $10 \mathrm{~K}$. Physica C 153, 1148-1152 (1988).

29. Kobayashi, H., Cui, H. B. \& Kobayashi, A. Organic metals and superconductors based on BETS (BETS $=$ Bis(ethylenedithio) tetraselenafulvalene). Chem. Rev. 104, 5265-5288 (2004).

30. Shimizu, Y., Miyagawa, K., Kanoda, K., Maesato, M. \& Saito, G. Spin liquid state in an organic Mott insulator with a triangular lattice. Phys. Rev. Lett. 91 , 107001 (2003).

31. Itou, T., Oyamada, A., Maegawa, S., Tamura, M. \& Kato, R. Spin-liquid state in an organic spin-1/2 system on a triangular lattice, $\mathrm{EtMe}_{3} \mathrm{Sb}\left[\mathrm{Pd}(\mathrm{dmit})_{2}\right]_{2} . J$. Phys.: Condens. Mater. 19, 145247 (2007).

32. Yamashita, $\mathrm{S}$. et al. Thermodynamic properties of a spin-1/2 spin-liquid state in a k-type organic salt. Nat. Phys. 4, 459-462 (2008).

33. Okamoto, Y., Yoshida, H. \& Hiroi, Z. Vesignieite $\mathrm{BaCu}_{3} \mathrm{~V}_{2} \mathrm{O}_{8}(\mathrm{OH})_{2}$ as a candidate Spin-1/2 Kagome antiferromagnet. J. Phys. Soc. Jpn. 78, 033701 (2009).

34. Isono, $\mathrm{T}$. et al. Gapless quantum spin liquid in an organic spin-1/2 triangularlattice $\mathrm{\kappa}-\mathrm{H}_{3}(\text { Cat-EDT-TTF) })_{2}$. Phys. Rev. Lett. 112, 177201 (2014).

35. Watanabe, K., Kawamura, H., Nakano, H. \& Sakai, T. Quantum spin-liquid behavior in the spin-1/2 random Heisenberg antiferromagnet on the triangular lattice. J. Phys. Soc. Jpn. 83, 034714 (2014).

36. Fu, M. X., Imai, T., Han, T. H. \& Lee, Y. S. Evidence for a gapped spin-liquid ground state in a Kagome Heisenberg antiferromagnet. Science 350, 655-658 (2015).

37. Aoyagi, S. et al. Structure of [60]fullerene with a mobile lithium cation inside. R. Soc. Open. Sci 5, 180337 (2018).

38. Aoyagi, S. et al. Tunneling motion and antiferroelectric ordering of lithium cations trapped inside carbon cages. J. Phys. Soc. Jpn. 85, 094605 (2016).

39. Ueno, $\mathrm{H}$. et al. Electrochemical reduction of cationic $\mathrm{Li}^{+} @ \mathrm{C}_{60}$ to neutral $\mathrm{Li}^{+} @ \mathrm{C}_{60} \cdot{ }^{-}$: isolation and characterisation of endohedral [60]fulleride. Chem. Sci. 7, 5770-5774 (2016).

40. Ueno, $\mathrm{H}$. et al. Ionic conductivity of $\left[\mathrm{Li}^{+} @ \mathrm{C}_{60}\right]\left(\mathrm{PF}_{6}{ }^{-}\right)$in organic solvents and its electrochemical reduction to $\mathrm{Li}^{+} @ \mathrm{C}_{60}{ }^{-}$. Chem. Commun. 49, 7376-7378 (2013).

41. Henke, W., Kremer, S. \& Reinen, D. Copper $(2+)$ in five-coordination: A case of a pseudo-Jahn-Teller effect. 1. Structure and spectroscopy of the compounds $\mathrm{Cu}$ (terpy) $\mathrm{X}_{2} \cdot n \mathrm{H}_{2} \mathrm{O}$. Inorg. Chem. 22, 2858-2863 (1983).

42. Godiksen, A. et al. Coordination environment of copper sites in $\mathrm{Cu}-\mathrm{CHA}$ zeolite investigated by electron paramagnetic resonance. J. Phys. Chem. C. 118, 23126-23138 (2014).

43. Reed, C. A. \& Bolskar, R. D. Discrete fulleride anions and fullerenium cations. Chem. Rev. 100, 1075-1119 (2000).

44. Nag, A. \& Ray, S. Misjudging frustrations in spin liquids from oversimplified use of Curie-Weiss law. J. Magn. Magn. Mater. 424, 93-98 (2017).

45. Ramirez, A. P. Strongly geometrically frustrated magnets. Annu. Rev. Mater Sci. 24, 453-480 (1994).

46. Kitagawa, K., Takayama, T., Matsumoto, Y., Kato, A., Takano, R. \& Kishimoto, Y. et al. A spin-orbital-entangled quantum liquid on a honeycomb lattice. Nature. 554, 341 (2018).

47. Dolomanov, O. V., Bourhis, L. J., Gildea, R. J., Howard, J. A. K. \& Puschmann, H. OLEX2: A complete structure solution, refinement and analysis program. J. Appl. Crystallogr. 42, 339-341 (2009).

48. Chilton, N. F., Anderson, R. P., Turner, L. D., Soncini, A. \& Murray, K. S. PHI: A powerful new program for the analysis of anisotropic monomeric and 
exchange-coupled polynuclear d- and f-block complexes. J. Comput. Chem. 34, 1164-1175 (2013).

49. Xiao, M. \& Lu, T. Generalized charge decomposition analysis (GCDA) method. J. Adv. Phys. Chem. 04, 111-124 (2015).

50. Frisch, M. J. et al. Gaussian 16. Rev. C.01. Wallingford, CT https:// gaussian.com/citation/ (2016).

51. Lu, T. \& Chen, F. W. Multiwfn: A multifunctional wavefunction analyzer. J. Comput. Chem. 33, 580-592 (2012).

\section{Acknowledgements}

This work was supported by JSPS KAKENHI Grant Numbers JP19H05631 (S.T. and M.Y.). M.Y. acknowledges the support of the 111 Project (B18030) from China. Computations were carried out using the computer resources offered under the category of the Trial Use Project by the Research Institute for Information Technology, Kyushu University.

\section{Author contributions}

Y.S. conceived and designed the project. Y.S. synthesised, characterised, and analysed all compounds. M.C. measured the optical spectra. K.S. measured low-temperature singlecrystal X-ray diffraction. E.K., K.K. and Y.K. provided $\left(\mathrm{Li}^{+} @ \mathrm{C}_{60}\right)\left(\mathrm{NTf}_{2}\right)$ salt. Y.S., T.Y., N.H., and T.A. measured the EPR spectra. H.K and T.F. measured heat capacity. Y.S. performed and analysed the GCDA and DT-DFT calculations. Y.S. wrote the paper with input from M.Y., S.T., T.T.H.K. and A.O.

\section{Competing interests}

The authors declare no competing interests.

\section{Additional information}

Supplementary information The online version contains supplementary material available at https://doi.org/10.1038/s41467-022-28134-w.

Correspondence and requests for materials should be addressed to Yongbing Shen or Masahiro Yamashita.

Peer review information Nature Communications thanks Lipiao Bao and the other, anonymous, reviewer(s) for their contribution to the peer review of this work. Peer reviewer reports are available.

Reprints and permission information is available at http://www.nature.com/reprints

Publisher's note Springer Nature remains neutral with regard to jurisdictional claims in published maps and institutional affiliations.

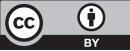

Open Access This article is licensed under a Creative Commons Attribution 4.0 International License, which permits use, sharing, adaptation, distribution and reproduction in any medium or format, as long as you give appropriate credit to the original author(s) and the source, provide a link to the Creative Commons license, and indicate if changes were made. The images or other third party material in this article are included in the article's Creative Commons license, unless indicated otherwise in a credit line to the material. If material is not included in the article's Creative Commons license and your intended use is not permitted by statutory regulation or exceeds the permitted use, you will need to obtain permission directly from the copyright holder. To view a copy of this license, visit http://creativecommons.org/ licenses/by/4.0/.

(C) The Author(s) 2022 